\title{
Influence of Social Media, Self-Esteem and Emotional Instability on Socio-Emotional Adjustment of Fresh Undergraduates of University of Ibadan
}

\author{
Afusat Olanike Busari* and Olawumi Ifedapo Atinuke \\ Department of Counselling and Human Development Studies, University of Ibadan, Nigeria
}

Submission: May 10,2019; Published: May 30, 2019

*Corresponding author: Afusat Olanike Busari, Department of Counselling and Human Development Studies, University of Ibadan, Ibadan, Nigeria

\begin{abstract}
This study examined the influence of social media, self-esteem and emotional instability on socio-emotional adjustment of fresh undergraduates of University of Ibadan. A sample of three hundred students was randomly sampled from the University of Ibadan, Ibadan Oyo state. The study adopted descriptive design of expo-facto type. Data was collected using four reliable instruments (socio-emotional scale $\alpha=.77$; social media scale $\alpha=0.67$; self-esteem scale $\alpha=0.72$; emotional instability scale $\alpha=0.80$ ). Three research questions were raised and tested using Pearson's product moment correlation and multiple regression analysis. It was discovered that social media $(\mathrm{r}=-.066$, $\mathrm{p}<.005)$, self-esteem $(\mathrm{r}=.383, \mathrm{P}<0.05)$ and emotional instability $(\mathrm{r}=.255, \mathrm{P}<0.05)$ significantly correlated with socio-emotional adjustment. From the regression analysis, it was discovered that social media, self-esteem and emotional instability jointly predicted socio-emotional adjustment. This suggests that the three factors combined accounted for $17.1 \%$ (Adj.R2 $=.171$ ) variance in the prediction of socio-emotional adjustment. More so, selfesteem was found to be the strongest predictor of socio-emotional adjustment, followed by emotional instability, while social media was the least predictor of socio-emotional adjustment. Based on the findings of the study, it was recommended that school counselors should organize adjustment boosting programmes that is capable of reducing students' socio-emotional maladjustment as well as have one on one relationship with students in the university so as to help students develop high self-esteem and well-adjusted lifestyle.
\end{abstract}

Keywords: Social media; Self- esteem, Emotional instability; Socio-emotional adjustment; Fresh Undergraduates

\section{Introduction}

Nothing is created or designed by nature to remain constant. Plants and animal evolves, human organisms develop from zygote to senescence and pass through different stages of life, at each of these stages, different challenges, crises, needs, wants are faced, new form of challenge at each new stage. For an individual to become an all-round person with considerable psychological wellbeing, adjustment to the stages is not an option but a core. The university is a new environment that triggers different reactions among first year students. Thus, life at university for the first year can be exciting and challenging [1]. The transition to university exposes students to considerable academic, social and emotional challenges.

For many students, starting university is a challenging and stressful experience that involves significant life change and adaptation to a variety of demands [2]. Empirical evidence suggests that the degree to which students are able to successfully adjust to university life may affect their well-being, academic performance and whether they persist with their course of study [3]. In terms of academic challenges, one of the more obvious and inevitable is that students are required to engage in more intellectually demanding work than previously undertaken, since tertiary-level education requires students to develop skills such as critical thinking and academic writing.

Moreover, these increased academic demands may result in students receiving marks or feedback that are worse than they expect, or to which they have previously been accustomed, with associated detrimental effects on the individual. The incoming student may also need to adapt to new approaches to teaching and learning at tertiary level, classes are frequently large and impersonal, and students are required to take a greater responsibility for their own learning than in earlier educational environments, [4]. These challenges may be exacerbated by the fact that students frequently underestimate how different university will be in comparison to prior educational experiences, particularly with regard to the level of autonomy required. In a similar vein, students have reported feeling that their pre-university educational experiences have not adequately prepared them to study at degree level.

In addition to these academic concerns, the transition to a new and unfamiliar environment requires social and interpersonal 
adaptations. For some students, starting university may represent the first significant separation from the home, family and friends. Associated with this is the leaving behind of existing sources of support [5] and the need to alter and restructure existing relationships. Moreover, new relationships need to be created; unsurprisingly, many new University students report feeling lonely or homesick at this time [6]. Turning to personal challenges, the transition to higher education involves issues relating to role change and establishing one's identity. Students also need to familiarize themselves with their new environment and establish a new lifestyle and new routines.

The early months of university may also involve emotions and reflections associated with the experience of starting university, and whether the decision to undertake a degree (or to attend the chosen university in particular) was sound. For example, students frequently encounter uncertainties and problems in relation to discipline choice [7] and may feel disillusioned and disappointed if the reality of the university experience has failed to meet expectations [8,9]. Pressures may be further compounded by worries over finances [10], and there may be the necessity to undertake paid work whilst studying, presenting further demands on the student's time and resources. Adjustment is a generic term; many scholars have attempted to define adjustment. The general meaning of adjustment is proper adaption or maintaining balance in the environment. In English language, the word adjustment is used for the process of adaption, it means to shift lightly. Adjustment is a process of maintaining equilibrium in all spheres of life, ranging from social, emotional, psychological, educational, marital etc. aspect of human life. Hence, adjustment is a process of arranging individual behavior properly. Different authors have given different definitions of adjustment. According to [10], adjustment is effectiveness of individual's attempts to maintain balance between satisfaction, needs and environment. define adjustment as a process of interaction between people and their environment in which either they adapt with the environment or change the environment. Adjustment is a process of maintaining balance between needs and the circumstance affecting needs [11].

Adjustment is the most important sign of psychological health. It is related to human's affective, social, educational, marital, emotional, and occupational domains. [12] believes that adjustment level and psychological health are the result of association between ego and experiences [13]. adjustment in adolescents can be analyzed from emotional, social and educational standpoints. Social adjustment is the individuals' adjustment with their social surrounding that can be gained by changing the self or the environment [14]. Emotional adjustment is the realization of one's emotions and feelings and controlling feelings when making relationships with others. One of the aspects that play a pertinent role in promoting healthy development is socio-emotional adjustment. It reflects an individual's well-being in emotions, personality, relationships with other people and within the social contexts [15]. Putting these two domains together, socialization is achieved through communication which loaded with emotions; meanwhile, university freshmen adjust their relationships with others to fulfill the emotional needs. Socio-emotional adjustment is on the main factor in academic achievement [7].

Whilst a successful and smooth adaptation to university life is a desirable and important outcome in its own right [16], it is also significant due to its relationship to key indicators of student and institutional success. Socio-emotional adjustment can be examined in terms of how well students' function in their immediate environment, participation in social activities, have positive emotion about self, can cope under duress and negative emotional atmosphere and their satisfaction with various social aspects of the university experience. The social environment of college requires adjustment on the part of new college students. The student has to fit within groups the student cares about, both inside and outside the university [12]. Socio-emotional adjustment refers to the psychological distress and somatic symptoms associated with the adjustment process. Freshmen are concerned with being part of the university. They also want to prove themselves to their peers. Emotional adjustment affects achievement in an indirect way.

Student adaptation and adjustment into the university system are central aspects of numerous theoretical models of student development, persistence and withdrawal. Students who experience significant adjustment difficulties are likely to discontinue enrolment [17]. Adjustment to university has also been empirically related to academic achievement. Students are at greatest risk of dropout during their first year $[7,18]$. Adjusting to university involves the complementary processes of desocialization and socialization [13]. Desocialization entails the changing or discarding of selected values, beliefs and traits one brings to university in response to the university experience. [13] explained socialization as the process of being exposed to and taking on some of the new values, attitudes beliefs and perspectives to which one is exposed at university. Upon entry into a university, first year students are confronted with new personal and interpersonal challenges that include the need to establish new relationships, develop study skills and modify existing relationships with parents and their families Parker.

The world is becoming a global world through the activities of media. As a result of this, behaviors are being influenced. Social media sites are fast becoming very popular means of both interpersonal and public communication. Social networking sites are modern interactive communication channels through which people connect to one another, share ideas, experiences, pictures, messages and information of interest [19]. With the current trend toward spending more time online, attention has turned 
to how new, internet-based social networks have revolutionized the way people connect, interact, and network with each other [20]. The ubiquity of the social media sites within their short period of arrival is unparalleled in the annals of media industry. [21] buttresses this point by noting that "social networking has become hugely popular, unlike radio, television that took many years to reach wider audience. Thus, since inception, social networking sites like Facebook, twitter,2go, My Space, Skype etc. have engaged millions of users, many of whom have been made to use these sites as parts of their daily activities [22].

The emergence of social media has created opportunities to establish peer-support networks prior to students arriving on campus in ways that may not have been previously possible without the affordances of new media. Indeed, social media websites are being developed by universities to increase connections among graduate students, faculty, and staff across distributed campuses. Social network sites have received considerable attention from researchers and the general public alike due to the increasingly large user-base for sites like Facebook. Facebook, in particular, has shown that students may reap social benefits from using the site [23]. Researchers have argued that social media sites like Facebook have the ability to guide students entering an unfamiliar social environment [24]. suggest that social network sites offer a unique opportunity to promote socialization to the college environment. It was further argued that social network sites can help students learn about their peers and college which, in turn, can create satisfaction and adjustment with the University. Research on social network sites does not unequivocally conclude that increased usage of social media will result in positive outcomes [14].

Other forms of communication technology have been shown to help students in educational settings. In particular, web logs (blogs) have been utilized for a variety of educational purposes. Having the ability to seek out help and express feelings and concerns has been shown to play a role in students' adjustment to college. On the other hand, violence is one of the dominating messages disseminated through the sensation of media, which plays an active role in entertaining and impacting the lives of today's young audience. The influence of televised violence on socio-emotional and academic adjustment of students has been largely associated with imbibing new ways of life. These ways affect social, emotional and mental adjustment. The growth and popularity of social networking sites have generated concerns among school authorities, communication experts and sociopsychological researchers about the benefit and potential risks facing undergraduates, as they engage in online social networking to cater for their social and information needs rather than oral or face-to-face communication. Stability in emotions means firmly established or fixed, not easily upset or disturbed, well balanced and capable to remain in same status. Emotional stability is a personality dimension which determines a person's capacity to stay calm or even capsize when exposed to pressure or stress. The fruits of normal emotionality can be obtained from the notion of stable emotional behavior at any level. Emotionally unstable people are more volatile; such person faces an increased risk of reacting violently and with harmful behaviors when coping with stress. In general, the ability of persons to recognize the triggers that induce stress and build healthy coping skills tends to maintain emotional stability [25].

The person who lacks this ability shows an emotional instability. Majority of students admitted into the university are still in their puberty stage which is characterized by strong negative emotions such as fear, worry, distress and anger and this can be injurious to the health and adjustment of the students if not properly managed. People who score low on the trait emotional stability tend to experience such negative feelings as anxiety, embarrassment, inability to adapt and low self-esteem. Person's emotional traits are one of the needed aspects of socioemotional adjustment and are more stable in persons with high emotional stability. It is a fact that emotionally stable people show better self-control on themselves than that of emotionally wobbly people, emotional stability is an important component of individuals in their social and emotional adjustment.

Stable emotional behavior at any level is that which reflects the fruits of the normal emotional development. An individual who is able to keep his emotions stable and under control even in extreme situations, might still be emotionally stunned or be childish in his behavior sometimes [25]. opined that emotional stability is one of the seven important indicators of superior mental health which affects the adjustment of students. Emotional instability may impair performances in situations which require flexibility and adaptability on the part of the person or students. Emotions are built on social context, and it has its own place for social acceptance of the social system. Thus, a person's emotional actions stable or unstable hold the impact of that person's social adjustment. Emotions can be understood as socially constructed, transitory roles, which are socially built as they initiate in our judgments of circumstances. They are transitory in that they are time limited. University places more emphasis on the learning of knowledge rather than on students' frame of mind. Yet students feel nervous, anxious, frustrated, depressed and abased when instructors ignore their emotions. If students cannot receive timely guidance from school authorities, teachers or their parents or timely concern from their peers or siblings, then their unstable emotions may result in behavioral and adaptation problems [12].

Also, self-esteem is another important factor to be considered when it comes to adjustment. Self-esteem is a sense of being valued, resulting from our personal thoughts, feelings, emotions and experiences in life. Self-esteem reflects an individual's overall subjective emotional evaluation of his or her own worth. It is the decision made by an individual as an attitude towards the [26]. For example, humans think that they are smart or stupid, good or bad. Thousands of impressions, 


\section{Open Access Journal of Neurology \& Neurosurgery}

assessments and experiences make man pleasantly feel valued or unpleasantly feel inadequate. Self-esteem is the individual value of self-concept information, resulting from his beliefs about his traits and features. Hence, individual's self-esteem is based on a combination of the objective information about himself and subjective values that he holds for that information [27].

Self-esteem is highly implicated on students' socio-emotional adjustment. The transition to university is considered to be a challenging and stressful life event. It was pointed out by that two types of stress cause high anxiety in students. One is related to academic expectations and performance and the other one is related to social factors, such as developing and maintaining interpersonal relationships. emphasized on the necessity of the self-esteem and stated that it is a factor determining the various forms of the individual behaviors. Students experience physical and psychological problems in light of their transition to university. The prevalence of maladjusted behavior among fresh undergraduates in university is alarming and a major concern to parents, counsellors, and the university authorities. Many students have difficulty in adjusting to the socioemotional demanding of university thereby exhibiting antisocial behavior such as lateness to class, lackadaisical attitude to academic activities, low tolerance level to peers and social demands, assertiveness problems, and difficulty experiencing positive emotions. The enormity of this on the students, parents, significant others and the society at large is huge, as inability to adjust to socio-emotional demands of university can leads to host of problems which can affect the academic achievement, careers and psychological health of an individual and significant others.

Evidence abounds in the society, especially in the university environment where students who have attained some height in their educational career (that is, being an undergraduate) are exhibiting behavior that are divergent to their status and in dissonance to societal norms. Many fresh students revert to prostitution, bribing lecturers with money and seduction cum coitus in order to obtain high grades. Also, many students engage in cyber-crime (yahoo), sophisticated examination malpractice, secret cults and becoming a tool in the hand of politician to be manipulated and used for violent and illegal electoral activities. Students, especially the fresh undergraduates, are implicated in all these afore mentioned behaviors due to their inability to achieve socio-emotional adjustment in the university environment [8].

In recent times, there are records of prevalence of antisocial behavior such as prostitution, sophisticated examination malpractice among undergraduates in university. This is evident in the obvious increased rate of crime, moral decadence, lackadaisical attitude and delinquency in society perpetrated by students of tertiary institution, as many students engage in much socially undesirable behavior such as cultism, robbery and cybercrime. This pathetic situation is traceable to adjustment problem and fueled an examination into social media, self- esteem and emotional instability and how they influence socioemotional adjustment of university fresh undergraduates.

Student success and well-being are critical considerations for institutions; hence, the discussion of university socio-emotional adjustment has become the focus of much research effort. As socio emotional maladjustments have been notoriously hard to treat, there is a growing attention on prevention and early intervention. Hence, an investigation into factors that influence socio-emotional adjustment among fresh undergraduates is worthy enterprise. While studies have been conducted on socio-emotional adjustment of students in other countries, there is paucity of such in Nigeria, and this study aim to fill this gap by unraveling the influence of social media, self-esteem and emotional instability on socio-emotional adjustment of university freshmen among university of Ibadan undergraduate.

\section{Purpose of the Study}

The main purpose of this study is to examine the influence of social media, self-esteem, emotional instability on socioemotional adjustment of university freshmen. The specific objectives of this study are to

a. determine the relationship between the independent variables (social media, emotional instability, self-esteem and (socio-emotional adjustment)

b. examine the joint contribution of the independent variable (social media, emotional instability, self-esteem) to the prediction of dependent variable (socio-emotional adjustment)

c. establish the relative contribution of each of the independent variables (social media, emotional instability, self-esteem) to dependent variable (socio-emotional adjustment)?

\section{Research Questions}

The following research questions guided this study.

a. What is the relationship between the independent variables (social media, emotional instability, self-esteem and (socio-emotional adjustment)?

b. What is the joint contribution of the independent variables (social media, emotional instability, self-esteem) to the prediction of dependent variable (socio-emotional adjustment)?

c. What is the relative contribution of each of the independent variables (social media, emotional instability, self-esteem) to dependent variable (socio-emotional adjustment)?

\section{Design}

The descriptive research design of the ex-post facto type was adopted for this study. Ex-post facto research is a systematic empirical research in which the researcher does not have direct 
control over independent variables because their manifestations have already occurred or because they are inherently not manipulated. Inferences about relations among variables are made without direct interaction with independent and dependent variables.

\section{Sample and sampling techniques}

This study adopted stratified and simple random sampling technique, whereby the faculties in the University of Ibadan were grouped into strata based on pure science, environmental science, and humanities/behavioral science related discipline. There are 11 faculties of which some are more populated than others. The highly populated faculties are education, social science, science, agriculture and forestry, and art, while college of medicine, pharmacy, veterinary medicine, and technology are moderately populated. 195 participants comprised of $65 \%$ of the total sample size was randomly selected from the highly populated faculties while the remaining 105 participants comprised of $35 \%$ was randomly selected from the moderately populated faculties. In whole, 300 fresh undergraduates who were willing to participate in the study were selected across the faculties.

\section{Instruments}

Four reliable instruments were used to elicit information for this study.

\section{School Adjustment Scale (SAS)}

School Adjustment Scale (SAS) is 19 item rating scale developed. It was adapted by the researcher to measure the rate of student's adjustment. It consists of two sections. Section A consists of demographic information such as age, gender, marital status, religion, and faculty. The scale adopted 4-point response formats ranging from strongly agree to strongly disagree with smallest number representing poor adjustment of the students. A pilot study was carried out to ascertain the suitability of the instrument in the measurement of socio-emotional adjustment. After the analysis 4 items were discarded and alpha of 0.77 was obtained for the remaining 15 items which was used in the study. Examples of the items in the scale include; "Worried about the impression you make on others", "felt optimistic about your future at college".

\section{Rosenberg Self-esteem Scale (RSE)}

Rosenberg self -esteem scale is a 10 -item rating scale developed by Rosenberg. The scale measured students' selfesteem level. The scale adopted 4-point response formats ranging from strongly agree to strongly disagree with higher number representing presence of high self-esteem. Through pilot study, Cronbach alpha of 0.72 was obtained. Examples of the items include; "On the whole", "I am satisfied with myself; I think that I have a number of good qualities".

\section{Emotional Instability Scale}

Emotional instability scale developed. The scale is a 4-point scale ranging from strongly agrees to strongly disagree. After pilot study, 6 items were removed from the total of 20 items due to the fact that the items are not reliable; hence, the remaining 14 items were retained. Coefficient alpha of 0.80 was obtained. Examples of the items in the scale include: "When I am upset, I try not to show it", “I don't know when something will upset me or not".

\section{Social media scale}

This scale measure social media usage of the students. It is a 16-item rating scale, ranging from strongly agree to strongly disagree which was developed by. After pilot study, two items were removed from the scale thereby retaining the remaining 14 items. Alpha of 0.67 was observed. Examples of items in the scale includes; "I engage in academic discussions on twitter and this has improved my adjustment", "I will not adjust well in my academics even if I stop using social media".

\section{Procedure for Data Collection}

Permission was sought from the Students' Affairs office of the University in order to conduct the research. The questionnaires were administrated to the respondents at their various faculties. The respondents were adequately briefed on the importance of the study; they were also assured of the confidentiality of their responses. The questionnaires were administered to randomly selected respondents from University of Ibadan, Oyo State. The administration of the questionnaires lasted two weeks.

\section{Method of Data Analysis}

The data collected for the study were analyzed using descriptive statistics of frequency counts, simple percentage for section A, while Pearson Product Moment Correlations (PPMC) and Multiple Regression Analysis was used to analyze the research questions.

\section{Results}

\section{Demographic Characteristics of Respondents}

This segment presents the descriptive statistics of gender, religion, age and faculty. Table 1 reveals that $54.3 \%$ of the respondents were male, while $45.7 \%$ of the respondents were female. This implies that males participated more in this study than their females' counterparts.

Table 1: Frequency Distribution of respondents by Gender.

\begin{tabular}{|c|c|c|}
\hline Social network & Frequency & Percentage \% \\
\hline Male & 163 & 54.3 \\
\hline Female & 137 & 45.7 \\
\hline Total & 300 & 100 \\
\hline
\end{tabular}




\section{Open Access Journal of Neurology \& Neurosurgery}

Table 2: Frequency Distribution of respondents by Religion.

\begin{tabular}{|c|c|c|}
\hline Religion & Frequency & Percentage \% \\
\hline Christian & 180 & 60 \\
\hline Muslim & 120 & 40 \\
\hline Total & 300 & 100 \\
\hline
\end{tabular}

Table 3: Frequency Distribution of respondents by Age.

\begin{tabular}{|c|c|c|}
\hline Age & Frequency & Percentage \% \\
\hline $16-20 y r s$ & 241 & 80.3 \\
\hline $21-25 y r s$ & 44 & 14.7 \\
\hline 26-and above & 15 & 5 \\
\hline Total & 300 & 100 \\
\hline
\end{tabular}

Table 4: Frequency Distribution of respondents by Faculty.

\begin{tabular}{|c|c|c|}
\hline Faculty & Frequency & Percentage \% \\
\hline Education & 100 & 33.3 \\
\hline Social science & 54 & 18 \\
\hline Science & 44 & 14.7 \\
\hline Agriculture & 29 & 9.7 \\
\hline Others & 73 & 24.3 \\
\hline Total & 300 & 100 \\
\hline
\end{tabular}

Table 5: Correlation Matrix Showing the Relationship between Study Variables.

\begin{tabular}{|c|c|c|c|c|c|c|}
\hline Variables & Mean & Std. Dev & $\mathbf{1}$ & $\mathbf{2}$ & $\mathbf{3}$ \\
\hline Socio-emotional & & & & & \\
\hline adjustment & 32.615 & 4.58031 & 1 & & \\
\hline Self-esteem & 21.4799 & 2.92772 & $.383^{* *}$ & $.279^{* *}$ & 1 & \\
\hline Emotional instability & 32.5083 & 4.55111 & $.255^{* *}$ &.-066 & 0.067 & 0.027 \\
\hline Social media & 37.0251 & 5.19296 &. & 1 \\
\hline
\end{tabular}

Table 5 reveals the relationship of each independent variable (self-esteem, emotional instability and social media) with the dependent variable (socio-emotional adjustment); socioemotional adjustment positively correlated with self-esteem $(\mathrm{r}=$

$.383, \mathrm{p}<0.05)$, emotional instability $(\mathrm{r}=.255, \mathrm{p}<0.05)$, and social media $(r=-.066, p<0.05)$. This implies that the higher the selfesteem, emotional instability and socio-media usage, the higher the likelihood of socio-emotional adjustment.

\section{Research question 2}

Table 6: Summary of Multiple Regression Analysis for the Joint Contributions of Independent Variables to the Prediction of Socio-Emotional Adjustment.

\begin{tabular}{|c|c|c|c|c|c|}
\hline \multicolumn{7}{|c|}{$\begin{array}{r}\text { R }=.423 \text { R Square }=.179 \text { Adjusted R square } \\
=.171 \text { Std. Error }=4.17849\end{array}$} & Sig. \\
\hline Model & Sum of Squares & DF & Mean Square & 21.421 & $.000 \mathrm{~b}$ \\
\hline Regression & 1122.009 & 3 & 374.003 & & \\
\hline Residual & 5150.624 & 295 & 17.46 & & \\
\hline Total & 6272.634 & 298 & & & \\
\hline
\end{tabular}

What is the joint contribution of the independent variables (self-esteem, emotional instability and social media) on the dependent variables (socio-emotional adjustment)? Table 6 shows significant joint contribution of the independent variables (self-esteem, emotional instability and social media) to the prediction of socio-emotional adjustment. The result yielded a coefficient of multiple regressions $\mathrm{R}=0.423$ and multiple $\mathrm{R}$-square $=0.179$. This suggests that the three factors combined accounted for $17.1 \%$ (Adj.R2= .171) variance in the prediction of socio-emotional adjustment. The other factors accounting for the remaining variance are beyond the scope of this study. The ANOVA result from the regression analysis shows that there was a significant influence of the independent variables on socioemotional adjustment, $\mathrm{F}(3,295)=21.421, \mathrm{P}<0.05 . \eta 2=0.18$, this implies that the independent variable has little effect in the variation of dependent variable. 


\section{Open Access Journal of Neurology \& Neurosurgery}

\section{Research question 3}

What is the relative contribution of the independent variables (self-esteem, emotional instability and social media) on the dependent variables (socio-emotional adjustment)? Table 7 indicates that two out of three predictors (self-esteem, emotional instability) were potent predictors of socio- emotional adjustment. The most potent factor was self-esteem $(\beta=.344$, $\mathrm{t}=7.069, \mathrm{P}<0.05)$, followed by emotional instability $(\beta=.162$, $\mathrm{t}=13.442, \mathrm{P}<0.05)$, except social media $(\beta=-.093, \mathrm{t}=48.254$, $\mathrm{P}>0.05$ ) which had negative correlation with the dependent variables. This in a nutshell implies that, an increased influence of self-esteem will improve socio- emotional adjustment by $34.4 \%$, emotional instability will increase socio-emotional adjustment by $16.2 \%$.

Table 7: Relative Contribution of the Independent Variables to the Prediction of Socio-Emotional Adjustment.

\begin{tabular}{|c|c|c|c|c|c|c|}
\hline \multicolumn{2}{|c|}{ Model } & \multicolumn{2}{c|}{$\begin{array}{c}\text { Unstandardized } \\
\text { Coefficients }\end{array}$} & $\begin{array}{c}\text { Standardized } \\
\text { Coefficients }\end{array}$ & Sig. \\
\hline \multirow{4}{*}{1} & (Constant) & B & Std. Error & Beta & 8.425 & 0 \\
\cline { 2 - 7 } & Self-esteem & 18.792 & 2.723 & & 7.069 & 0 \\
\cline { 2 - 7 } & $\begin{array}{c}\text { Emotional } \\
\text { instability }\end{array}$ & 0.539 & 0.086 & 0.344 & 13.44 & 0.003 \\
\cline { 2 - 7 } & Social- media & 0.163 & 0.055 & 0.162 & 48.25 & 0.079 \\
\cline { 2 - 7 } & & -0.082 & 0.047 & -0.093 & & 0 \\
\hline
\end{tabular}

\section{Discussion}

The first research question examined the relationship between the independent variables (self-esteem, emotional instability and social media) and the dependent variable (socioemotional adjustment). The result obtained shows that socioemotional adjustment positively correlated with self- esteem, followed by emotional instability except social media that has negative relationship with socio-emotional adjustment. Thus, this finding implies that high influence of self-esteem and emotional instability will increase socio-emotional adjustment. High influence of social media use will reduce socio-emotional adjustment. This study supported the study of finds out that there is a positive correlation between socio-emotional adjustment and self-esteem. Similarly, [28] reported a significant relationship between self-esteem and social adjustment. Also, found that after controlling for baseline depression, levels of implicit, but not explicit, self-esteem significantly predicted adjustment levels six months later, suggesting that implicit selfesteem may be an important factor to study when examining overall socio-emotional adjustment. observed that emotional stability was positively and significantly related to adjustment and morality [28]. found that students who have high levels emotional stability are better adjusted to overall college life. Also in support of the result obtained from the current study, [29] found that individuals who use social media to manage or regulate their social connections or affect (i.e., social-affective motive) experience more negative effects on their well-being and adjustment, including decreased social integration, increased negative effect, pathological internet use patterns, and less overall social and psychological health [30]. Found that while instant messaging was associated with positive adjustment, the use of social networking sites was associated with negative adjustment.

The present study therefore asserts that based on the result of the findings; self- esteem is a potent factor predicting socio-emotional adjustment. This therefore indicates that undergraduates that seek to be socio-emotionally adjusted to university environment should improve on self-esteem. Individuals who are very high in self-esteem tend to cope favorably with whatever challenges they face. Emotional instability is a factor to reckon with in the discussion of socioemotional adjustment. Undergraduate should be able to swing emotions in order to adjust to socio-emotional challenge of the day. The usage of social media for frivolities should be drastically reduced among undergraduate, as this prevent them to experience positive socio-emotional adjustment to the university environment [31-35].

The second research question examined the joint contribution of the independent variables (self-esteem, emotional instability and social media) to the prediction of the dependent variable (socio-emotional adjustment). The result reveals significant joint contribution of the independent variables (self-esteem, emotional instability and social media) to the prediction of socio-emotional adjustment. This result agreed with results of the World Health Organization Cross-National Collaborative Study of countries around the globe which indicates that about one-third or more of Canadian students reported high school maladjustment. Young children who exhibit healthy social, emotional, and behavioral adjustment are more likely to have good self-esteem, stable emotion and academic performance in university. From the findings of this study, self- esteem, emotional instability and social-media use collectively significantly predict socio-emotional adjustment. Socio-emotional adjustment of undergraduate is a function of constellation of factors which involves self-esteem, emotional instability and social media [3640].

The third research question examined the relative contribution of the independent variables (self-esteem, emotional instability, social media) on the dependent variables (socio-emotional adjustment). The result shows that two out 
of three predictors (self-esteem and emotional instability) were potent predictors of socio-emotional adjustment. The most potent factor was self-esteem, followed by emotional instability. This result corroborated with studies of the influence of self-esteem on socio- emotional adjustment. The student self- esteem had significantly positive associations with socioemotional adjustment. It was revealed in the study that selfesteem predicted increase in college adjustment and increase in emotional adjustment. This simply means that when students perceived that they had high self-esteem, they presented higher levels of effort and perseverance in learning, were more likely to feel that they belonged to a school and had higher socioemotional adjustment [41-46].

\section{Conclusion}

This study investigated influence of social media, selfesteem, and emotional instability on socio-emotional adjustment among fresh undergraduate. The result showed that self-esteem, emotional instability and social media significantly correlates with socio-emotional adjustment. While from the regression analysis joint and relative contribution were found having selfesteem as the strongest predictor of students' socio-emotional adjustment. By implication students maximum socio-emotional adjustment is a function of increased self-esteem, emotional stability and lesser social media usage.

\section{Recommendations}

Based on the findings of this study the following suggestions were made

School counselors should organize adjustment boosting programmes that is capable of reducing students' socioemotional maladjustment as well as have one on one relationship with students in the university so as to help students develop high self-esteem and adjusted lifestyle. Parents and school counsellor should endeavor to help students build confidence and adjust better to university environment. School administrators in Nigeria are enjoined to help students out of their maladjustment predicament by employing more than one school counselor and as well include counselling programmes in the general orientation Program for fresher. The stakeholders in the universities should initiate Program in the university environment that will aid students socio-emotional adjustment.

\section{References}

1. Habibah E, Noordin N, Mahyuddin RH (2010). Achievement motivation and self- Efficacy in relation to adjustment among university students. Journal of Social Sciences 6(3): 333-339.

2. Coleman S, Rowe C (2017) Remixing Citizenship: Democracy and young people's use of the internet a report for the carnegre young people's initiative.

3. https://www.forbes.com/sites/jeffbercovici/2014/06/24/still-moredata-shows-pinterest-passing-twitter-in-popularity/\#42fee8db74ee.

4. Ezeukwu G (2013) The effect of Televised Violence in GO Ibe (ed) Mass Communication: A functional Approach. Awka: Christon International Company.
5. Sufian N (2012) Introduction in Personality and Counseling, Taez: Faculty of Education.

6. Shrirali E, Golestanipour M (2017) The Relationship between Social Adjustment and Self-Esteem of the Female Students in Islamic Azad University of Ramhormoz, International Journal of Indian Psychology $4(3)$.

7. Cartney P, Rouse A (2016) The emotional impact of learning in small groups: highlighting the impact on student progression and retention, Teaching in HE 11: 79-91.

8. Adeoye, Ayodele 0 (2014) social adjustment and emotional stability. US Open Public Health Journal 1(1): 1-8.

9. Stefanone M, Jang CJ (2011) Writing for friends and family: The interpersonal nature of blogs. Journal of Computer Mediated Communication 13(1): 123-140.

10. Cooke R, Bewick BM, Barkham M, Bradley M, Audin, K (2012) Measuring, monitoring and managing the psychological well-being of first year university students. British Journal of Guidance\& Counselling 34: 505-517.

11. Nielsen (2012) State of the media: The social media report Nielsen, NM Incite.

12. Dickens WT (2006) Cognitive Ability the New Dictionary of Economics. Steve Durlauf, Efat NB (Eds) Benefits of Facebook friends: Social capital and College Students' use of Online Social Network Sites: Journal of Computer-mediated communication 12(4).

13. Boazman Janette, Sayler Michael (2011) Personal Well-Being of Gifted Students Following Participation in an Early College-Entrance Program Roeper Review 33(2): 76-85.

14. Kaplan Andreas M, Haelein Michael (2010) Users of the world. Unite: The Challenges of Opportunities of social media Business Horizons 53(1): 59-68.

15. Morgan C, Cotton SR (2011) The relationship between internet activities and depressive symptoms in a sample of college freshmen. Cyber psychol Behav 6(2): 133-142.

16. Grayson JJ (2014) Handbook of emotion regulation NY: Guilford Press, New York, USA.

17. Micheal RB (2014) Emotional intelligence: science \& myth. Cambridge, Massachusetts: The MIT Press.

18. Krause K, Hartley R, James R, McInnis C (2010) The first-year experience in Australian universities: findings from a decade of national studies. Canberra: Australian Department of Education, Science and Training.

19. Nielsen (2014) The digital consumer Consumer Report. The Nielsen Company, New York, USA.

20. Ferlander EJ (2013) Activation of latent self-schemas as a cognitive vulnerability factor for depression: The potential role of implicit selfesteem. Cognition and emotion 22: 1588-1599.

21. Awake (2011) What Should I know social networking? Part 1, p. 24-25.

22. Barker v (2016) Older adolescents motivations for social network site use: the influence of gender, group identity, and collective self-esteem. Cyberpsychol Behav 12(2): 209-213.

23. Essoungou AM (2011) Nigeria's April elections set new records in use of social media.

24. Yen JY, Ko CH, Yen CF, Chen SH, Chung WL, et al. (2008) Psychiatric symptoms in adolescents with internet addiction: Comparison with substance use. Psychiatry Clin Neurosci 62(1): 9-16.

25. Yu A, Tian Y, SW, Vogel D, Kwok RC (2010) Can learning be virtually boosted? An investigation of online social networking impacts. Computers \& Education 551494-1503. 


\section{Open Access Journal of Neurology \& Neurosurgery}

26. Scott A Wickman, Cynthia Campbell (2012) An analysis of how Carl Rogers enacted client-centered conversation with Gloria. Journal of Counseling \& Development 81 (2): 178-184.

27. Smith SM, Petty RE (2007) Personality moderators of mood congruency effects on cognition: The role of self-esteem and negative mood regulation. J Pers Soc Psychol 68(6): 1092-1107.

28. Sokan J (2013) Relationship between attachment styles and selfesteem among students. Of Islamic Azad University of Lorestan. Psychology master's thesis.

29. Cohen J, Cohen P (2015) Applied multiple regression/correlation for the behavioral sciences. $\left(2^{\text {nd }}\right.$ ed.) Hillsdale, New Jersey: Lawrence Erlbaum Associates.

30. Weiser EB (2008) The functions of internet use and their social and psychological consequences. Cyber Psycholo Behav 4(6): 723-743.

31. Windham RC (2008) The changing landscape of adolescent Internet communication and its relationship to psychosocial adjustment and academic performance. Dissertation Abstracts International 68: 12.

32. Deci EL, Ryan RM (2005) Human autonomy: The basis for true selfesteem. In MH Kernis (Eds.) Efficacy, agency, and self-esteem, Springer, New York, USA, (pp. 30-49).

33. Frank E, De Raedt R, De Houwer J (2008) Activation of latent selfschemas as a cognitive vulnerability factor for depression: The potential role of implicit self-esteem. Cognition and emotion 22: 15881599.

34. Greenwald AG, Banaji MR (2010) Implicit social cognition: Attitudes, self-esteem, and stereotypes. Psychol Rev 102(1): 4-27.

35. Hinton SA, Wood JV, Marshall MA, Brown JD (2011) Do people with low self-esteem really want to feel better? Self-esteem differences in motivation to repair negative moods. J Pers Soc Psychol 82(1): 128 147

36. Kalnes K (2013) Influence of social media use on adolescent females' perceptions of their body image. Pro Quest Dissertations and Theses Retrieved from.
37. Kang S (2007) Disembodiment in online social interaction: Impact of online chat onsocial support and psychosocial well-being. Cyber Psychology and Behav 10(3): 475-477.

38. Kiesler S, Kraut R (2012) Internet use and ties that bind. American Psychologist 54: 783-784.

39. Livingstone HA, Day AL (2008) Comparing the construct and criterionrelated validity of ability-based and mixed-model measures of emotional intelligence. Educational and Psychological Measurement 65: 757-779.

40. Rierdan J (2012) Internet-depression link? American Psychologist 54: 781-782.

41. Rosenberg M (1965) Society and the adolescent self-image. Princeton, NJ: Princeton University Press.

42. Rutter M (2008) Psychosocial resilience and protective mechanisms. American Journal of Orthopsychiatry 57(3): 316-331.

43. Sheldon P (2008) The relationship between unwillingness to communicate and students' Facebook use. Journal of Media Psychology 20: 65-75.

44. Srivastava S, Tamir M, Mc Gonigal KM, John OP, Gross JJ (2009) The social costs of emotional suppression: A prospective study of the transition to college. J Pers Soc Psychol 96(4): 883-897.

45. Valkenburg PM, Peter J (2009) Social consequences of the Internet for adolescents: A decade of Research. Current Directions in Psychological Science18: 1-5.

46. Wood JV, Heimpel SA, Man well LA, Whittington EJ (2009) This mood is familiar and I don't deserve to feel better anyway: Mechanisms underlying self esteem differences in otivation to repair sad moods. J Pers Soc Psychol 96(2): 363-380.

\section{Your next submission with Juniper Publishers will reach you the below assets}

- Quality Editorial service

- Swift Peer Review

- Reprints availability

- E-prints Service

- Manuscript Podcast for convenient understanding

- Global attainment for your research

- Manuscript accessibility in different formats

( Pdf, E-pub, Full Text, Audio)

- Unceasing customer service

Track the below URL for one-step submission https://juniperpublishers.com/online-submission.php 